\title{
INTERNATIONAL
}

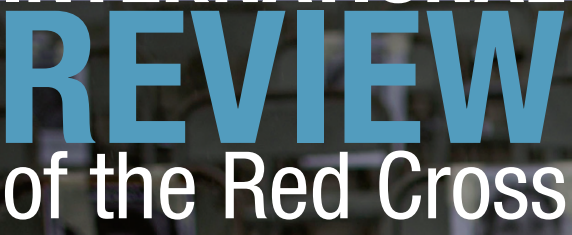

Humanitarian debate: Law, policy, action
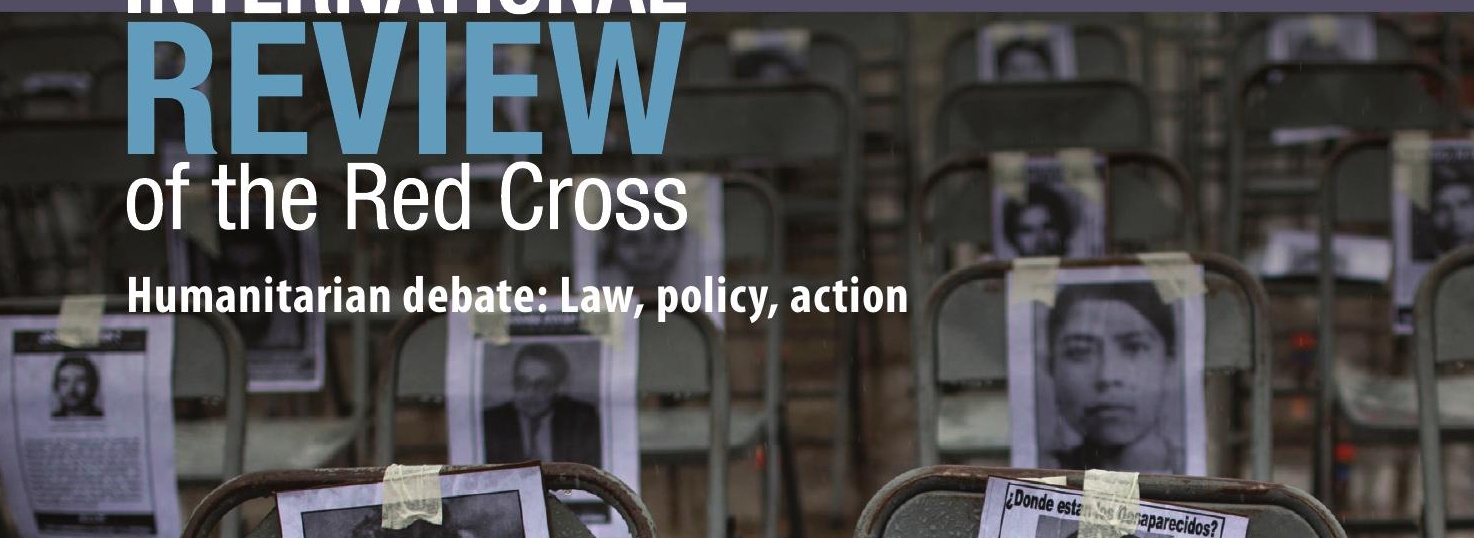


\section{REVIEW \\ of the Red Cross}

\section{Aim and scope}

Established in 1869, the International Review of the Red Cross is a peer-reviewed journal published by the ICRC and Cambridge University Press. Its aim is to promote reflection on humanitarian law, policy and action in armed conflict and other situations of collective armed violence. A specialized journal in humanitarian law, it endeavours to promote knowledge, critical analysis and development of the law, and contribute to the prevention of violations of rules protecting fundamental rights and values. The Review offers a forum for discussion on contemporary humanitarian action as well as analysis of the causes and characteristics of conflicts so as to give a clearer insight into the humanitarian problems they generate. Finally, the Review informs its readership on questions pertaining to the International Red Cross and Red Crescent Movement and in particular on the activities and policies of the ICRC.

\section{International Committee of the Red Cross}

The International Committee of the Red Cross (ICRC) is an impartial, neutral and independent organization whose exclusively humanitarian mission is to protect the lives and dignity of victims of war and other situations of violence and to provide them with assistance. It directs and coordinates the international activities conducted by the International Red Cross and Red Crescent Movement in armed conflict and other situations of violence. It also endeavours to prevent suffering by promoting and strengthening international humanitarian law and universal humanitarian principles. Established in 1863, the ICRC is at the origin of the Movement.

\section{Members of the Committee}

President: Peter Maurer

Vice-President: Christine Beerli

Mauro Arrigoni
Hugo Bänziger
François Bugnion
Gilles Carbonnier
Jacques Chapuis
Melchior de Muralt
Maya Hertig Randall
Alexis Keller
Jürg Kesselring

Thierry Lombard

Laura Sadis

Doris Schopper

Rolf Soiron

Béatrice Speiser

Bruno Staffelbach

Heidi Tagliavini

Barbara Wildhaber
Editorial Team

Editor-in-Chief: Vincent Bernard Managing Editor: Ellen Policinski Thematic Editor: Audrey Mackay Editorial Assistant: Jovana Kuzmanovic, Kvitoslava Krotiuk and Saman Rejali Book review editor: Jamie A. Williamson

Special thanks: Frédérique Desgrais, Jill Stockwell, Helen Obregon, Ximena Londono and Alexandra Ortiz Signoret

International Review of the Red Cross 19, Avenue de la Paix, CH 1202 Geneva CH - 1202 Geneva

$\mathrm{t}+41227346001$

e-mail: review@icrc.org

\section{Editorial Board}

Annette Becker

Université de Paris-Ouest Nanterre La Défense, France

Françoise Bouchet-Saulnier

Médecins sans Frontières, France

Emiliano Buis

University of Buenos Aires, Argentina

Hilary Charlesworth

Australian National University, Australia

Sarah Cleveland

Columbia Law School, US

Adama Dieng

UN Secretary-General's Special Adviser for the Prevention of Genocide, Senegal

Emanuela-Chiara Gillard

Institute for Ethics, Law and Armed

Conflict (ELAC), University of Oxford, UK

Fyodor Lukyanov

Russia in Global Affairs Journal; Council on Foreign and Defense Policy, Russia

Tasneem Meenai

Jamia Millia Islamia, India

Sorcha O'Callaghan

British Red Cross, UK

Emre Öktem

Galatasaray University, Turkey

Marco Sassòli,

University of Geneva, Switzerland

Michael N. Schmitt

US Naval War College, US

Sun Shiyan

Chinese Academy of Social Sciences

(CASS), China

Andrew Thompson

University of Exeter, UK

Cover Photo: Chairs bearing portraits of people who were disappeared during the 1980s sit empty in a ceremony marking the marking of the National Day fo the Disappeared in Guatemala City. 21 June 2017. Credit: Moises Castillo/Keystone. 


\section{NTERNATIONAL

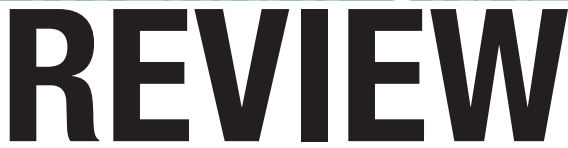 \\ of the Red Cross}

Humanitarian debate: Law, policy, action

\section{The Missing}




\section{CONTENTS}

\section{The missing}

475 Editorial: The disappeared and their families: When suffering is mixed with hope

Vincent Bernard, Editor-in-Chief

487 Interview with Estela Barnes de Carlotto

President of the Grandmothers of the Plaza de Mayo

The missing and their families

497 Families of the missing in Sri Lanka: Psychosocial considerations in transitional justice mechanisms

Maleeka Salih and Gameela Samarasinghe

519 Families of the missing: Psychosocial effects and therapeutic approaches

Pauline Boss

535 Q\&A: The ICRC's engagement on the missing and their families

547 Implementing international law: An avenue for preventing disappearances, resolving cases of missing persons and addressing the needs of their families

Ximena Londoño and Alexandra Ortiz Signoret

569 Protection of migrants from enforced disappearance: A human rights perspective

Bernard Duhaime and Andréanne Thibault 


\section{Missing person mechanisms}

589 Establishing mechanisms to clarify the fate and whereabouts of missing persons: A proposed humanitarian approach

Monique Crettol, Lina Milner, Anne-Marie La Rosa and Jill Stockwell

619 The Sri Lankan Office on Missing Persons: Truth and justice in tandem?

Isabelle Lassée

641 The Office on Missing Persons in Sri Lanka: The importance of a primarily humanitarian mandate

Vishakha Wijenayake

663 Determining the fate of missing persons: The importance of archives for "dealing with the past" mechanisms

Elisabeth Baumgartner and Lisa Ott

\section{Identifying the dead}

689 Using forensic science to care for the dead and search for the missing: In conversation with Dr Morris Tidball-Binz

709 Advances and progress in the obligation to return the remains of missing and forcibly disappeared persons

Dr Grażyna Baranowska

735 The first attempts in Mexico and Central America to address the phenomenon of missing and disappeared migrants Gabriella Citroni 


\section{Selected articles}

759 Management of the dead from the Islamic law and international humanitarian law perspectives: Considerations for humanitarian forensics

Ahmed Al-Dawoody

785 Adoption of the Additional Protocols of 8 June 1977: A milestone in the development of international humanitarian law

François Bugnion

797 Strengthening resilience: The ICRC's community-based approach to ensuring the protection of education

Geoff Loane and Ricardo Fal-Dutra Santos

\section{Reports and documents}

821 Announcement: Professors Emiliano Buis and Emanuela-Chiara Gillard join the Editorial Board of the International Review of the Red Cross

823 What's new in law and case law around the world?

Biannual update on national implementation of international

humanitarian law July-December 2016

Books and articles

841 New publication: The first two volumes of the updated Commentaries on the 1949 Geneva Conventions

843 International Law and New Wars Christine Chinkin and Mary Kaldor Book review by Daniele Archibugi 
847 Prosecuting Conflict-Related Sexual Violence at the ICTY Serge Brammertz and Michelle Jarvis (eds) Book review by Silke Studzinsky

853 New publications in international humanitarian law and on the International Committee of the Red Cross 